\title{
Cost per responder for ixekizumab and other biologic drugs approved for the treatment of moderate-to-severe plaque psoriasis in Italy
}

Global \& Regional Health Technology

Assessment

Volume 2019: I-9

(C) The Author(s) 2019

Article reuse guidelines: sagepub.com/journals-permissions DOI: 10.1 I77/22842403/8822289 journals.sagepub.com/home/grh @SAGE

\author{
Roberto Ravasio ${ }^{(1 D}$, Silvia Antonelli², Alessia Maiorino ${ }^{3}$, \\ Antonio Costanzo ${ }^{4,5}$ and Serena Losi ${ }^{3}$
}

\begin{abstract}
This analysis was aimed at estimating the cost per responder as measured by number needed to treat of ixekizumab as compared with other biologic drugs approved in Italy for the treatment of moderate-to-severe plaque psoriasis. The clinical efficacy was assessed in terms of number needed to treat, based on a network meta-analysis of published efficacy data as measured by Psoriasis Area and Severity Index response (PASI75, PASI90, and PASII00) for relevant biologic comparators. The cost was based on the number of administrations dispensed in the first (induction plus maintenance period) and the second (maintenance period only) year of treatment and the ex-factory price net of discounts of each biologic drug. The cost per responder was adopted as a cost-effectiveness indicator. Independent of the Psoriasis Area and Severity Index response (PASI75, PASI90, and PASII00) used and the year of treatment considered, the cost per number needed to treat for ixekizumab appeared consistently to be the lowest. For example, considering first-year costs and PASI75, the cost per responder for ixekizumab was $€ 16,388$, compared to adalimumab $(€ 22,574)$, etanercept (branded original: $€ 32,420$; biosimilar: $€ 2 I, 432)$, secukinumab (€I7,937), and ustekinumab $(€ 20,0 \mid 4)$. The differences in the cost per responder between ixekizumab and the comparators increased when higher Psoriasis Area and Severity Index response levels were considered. This economic assessment confirmed that ixekizumab is a cost-efficient option from the perspective of the Italian National Health Service for the treatment of moderate-to-severe plaque psoriasis.
\end{abstract}

\section{Keywords}

Plaque psoriasis, ixekizumab, adalimumab, etanercept, ustekinumab, secukinumab, cost per responder, number needed to treat

Date received: II September 2018; accepted: 6 December 2018

\section{Background}

Psoriasis is an inflammatory chronic skin disease, characterized by redness (erythema), thickness and scaling of the skin, and by remittance/relapse phases of variable length. ${ }^{1-3}$ It affects men and women in similar proportions, while the onset age is variable - though the disease most frequently occurs in young-adults. ${ }^{4}$

The typical cutaneous manifestations of psoriasis and its chronic course significantly interfere with the affected

\footnotetext{
'Health Publishing and Services Srl, Milan, Italy

2Eli Lilly Italia SpA, Roma, Italy

${ }^{3}$ Eli Lilly Italia SpA, Sesto Fiorentino, Italy

${ }^{4}$ Humanitas University, Milan, Italy

${ }^{5}$ Humanitas Research Hospital, Milan, Italy
}

Corresponding author:

Roberto Ravasio, Health Publishing and Services Srl, Piazza Duca

d'Aosta, 12, 20124 Milan, Italy.

Email: rravasio@aboutpharma.com 
subjects' quality of life (QoL), and can have a severe and sometimes disabling psychological and social impact. ${ }^{5}$ In fact, a high prevalence of anxiety, depression, and alcohol abuse is observed in patients with psoriasis. ${ }^{2}$ In addition to psychiatric comorbidities over the last few decades, psoriasis has been increasingly considered as a systemic disease, associated with several (rheumatologic, cardio metabolic, gastroenterological, etc.) comorbidities. In patients with severe psoriasis, a higher mortality risk (hazard ratio: 1.5; $95 \%$ confidence interval: $1.3-1.7$ ) is found as compared to the general population. ${ }^{4,6}$ Affected men and women, respectively, die 3.5 and 4.4 years earlier than healthy controls, probably due to comorbidities, lifestyle (smoke and alcohol abuse), and administered therapies. ${ }^{6}$

Psoriasis affects at least 100 millions of people all over the world, mostly Caucasians. ${ }^{4,7}$ Prevalence in Europe varies between $0.6 \%$ and $6.5 \%$, and is highest in northern countries. $^{8}$ Psoriasis in Italy, with about $1.5-2.5$ million cases, is one of the most common dermatological diseases, with a reported prevalence of $2.9 \%-3.1 \% 0^{9,10}$ and an incidence of 230-310 new cases per 100,000 persons/year. ${ }^{11}$

Plaque psoriasis (PsO) is the most common form $(80 \%$ ca. of all psoriasis patients). ${ }^{1-3}$ It is characterized by the presence of erythematous-desquamative lesions, located mainly at the extensor sites of the extremities (knees and elbows), the lumbosacral region and the scalp, ${ }^{1,2}$ often accompanied by burdensome symptoms such as itch and pain. ${ }^{3,12}$ In about $20 \%$ of cases, $\mathrm{PsO}$ is moderate to severe, defined by a Psoriasis Area Severity Index (PASI) score $>10$, or Body Surface Area (BSA) $>10$, or Dermatology Life Quality Index (DLQI) $>10$ according to the European S3-Guidelines and by the Italian guidelines SIDeMaST (Società italiana di Dermatologia medica, chirurgica, estetica e delle Malattie Sessualmente Trasmesse-Italian Society of Medical, Surgical, Cosmetic Dermatology, and Sexually Transmitted Diseases). ${ }^{13,14}$ A recent European consensus agreed to expand this definition of severity based on the presence of lesions in visible or so-called hard-totreat areas like the face, genitals, palms, and soles which can reduce the patients' QoL, even if PASI or BSA are $<10$. $^{13,14}$

As compared with traditional systemic therapies, biologic drugs have significantly changed the treatment pathways in moderate-to-severe PsO. ${ }^{15}$ Using biologic drugs, patients can now reach significant levels of skin clearance, associated with an improved QoL. 16,17

Several biologic drugs are currently available in Italy for the treatment of moderate-to-severe $\mathrm{PsO}$, including adalimumab, etanercept, infliximab (tumor necrosis factor (TNF)-alpha inhibitor), ustekinumab (interleukin-12/-23 inhibitor), and secukinumab (interleukin-17A inhibitor). Biosimilar drugs are currently available for etanercept and infliximab. AIFA (Agenzia Italiana del Farmaco-Italian Medicines Agency) has recently approved the reimbursement of ixekizumab, a new interleukin-17A inhibitor. In a series of clinical studies, ixekizumab has provided significantly higher efficacy in skin clearance compared with placebo, etanercept, and ustekinumab. ${ }^{18-20}$ Despite this clinical evidence, economic assessment of ixekizumab compared with other biologic therapies is currently unavailable regarding the Italian context. To address this gap for economic evaluation of ixekizumab versus other biologics indicated for the treatment of $\mathrm{PsO}$, we calculated the cost per responder, based on the NNT (number needed to treat). The cost per responder combines clinical and economic dimensions and provides additional support to for cost-effective decision-making.

\section{Objective}

Adopting the Italian National Health Service's (NHS) perspective (only direct medical costs were considered), this analysis was aimed at estimating the efficacy, the treatment costs, and the cost per responder of ixekizumab versus other biologic drugs approved in Italy for the treatment of moderate-to-severe PsO.

\section{Materials and methods}

The efficacy of approved systemic treatments for PsO treatment was assessed on the base of a series of outcome measurements taking into account the severity of symptoms..$^{14}$ PASI is one of the most frequently outcome measurement used; ${ }^{14}$ it combines a qualitative (presence of lesions such as erythema, infiltration, and desquamation) and quantitative (proportion of affected area for each body region) skin disease assessment. The PASI score can vary between 0 (no lesions) and 72 (disease highest degree). In addition, reduction of PASI based on the score variation from an initial value is used to classify the response to treatment as an improvement of at least 75\% (PASI75), or $90 \%$ (PASI90), or $100 \%$ (PASI100), respectively. ${ }^{14}$

To assess the cost per responder of the biologic therapies approved in Italy for the treatment of moderate-to-severe $\mathrm{PsO}$, the cost per NNT versus placebo was estimated. ${ }^{21,22}$ In general, the NNT is the number of patients in the experimental group who need to be treated in order to achieve one additional therapeutic benefit/responder patient (additional, that is, one more than the patients who would be successfully treated in the control group).

First, the NNT versus placebo of all biologic drugs was quantified using published study data (see the "Network meta-analysis" section). Second, multiplying the NNT by the corresponding treatment cost per patient, the cost per NNT of each biologic drug was evaluated.

\section{Dosing considerations}

Based on the Summary of Product Characteristics (SPC), the dosing scheme of the biologic therapies considered changes between the first (induction plus maintenance 
Table I. Dosing scheme, number of administrations, and annual mean cost per patient in the first year of treatment.

\begin{tabular}{|c|c|c|c|}
\hline Biologics & Dosage & $\begin{array}{l}\text { Number of } \\
\text { administrations } \\
\text { per year }\end{array}$ & $\begin{array}{l}\text { Annual mean } \\
\text { cost per patient }\end{array}$ \\
\hline Adalimumab & $\begin{array}{l}\text { Initial dose of } 80 \mathrm{mg} \text {, followed by a dose of } 40 \mathrm{mg} \text { administered every } \\
\text { other week, starting from the week following the administration of the } \\
\text { initial dose }\end{array}$ & 28 & $€|I, 88|$ \\
\hline $\begin{array}{l}\text { Etanercept } \\
\text { branded }\end{array}$ & $\begin{array}{l}\text { Initial dose of } 50 \mathrm{mg} \text { administered twice a week for } 12 \text { weeks, followed by } \\
\text { a dose of } 25 \mathrm{mg} \text { twice a week or } 50 \mathrm{mg} \text { once a week }\end{array}$ & 64 & $€ \mid 4,736$ \\
\hline $\begin{array}{l}\text { Etanercept } \\
\text { biosimilar }\end{array}$ & $\begin{array}{l}\text { Initial dose of } 50 \mathrm{mg} \text { administered twice a week for } 12 \text { weeks, followed by } \\
\text { a dose of } 25 \mathrm{mg} \text { twice a week or } 50 \mathrm{mg} \text { once a week }\end{array}$ & 64 & $€ 9742$ \\
\hline Ixekizumab & $\begin{array}{l}\text { Initial dose of } 160 \mathrm{mg} \text { administered at week } 0 \text {, followed by doses of } 80 \mathrm{mg} \\
\text { at weeks } 2,4,6,8,10 \text {, and } 12 \text {, then by doses of } 80 \mathrm{mg} \text { every } 4 \text { weeks }\end{array}$ & 17 & $€ 13,657$ \\
\hline Secukinumab & $\begin{array}{l}\text { Initial dose of } 300 \mathrm{mg} \text { at weeks } 0,1,2,3 \text {, and } 4 \text {, followed by a monthly } \\
\text { maintenance dose. Each dose of } 300 \mathrm{mg} \text { is administered with two } \\
\text { subcutaneous injections of } 150 \mathrm{mg} \text {. }\end{array}$ & 16 & $€ \mid 3,797$ \\
\hline Ustekinumab & $\begin{array}{l}\text { Initial dose of } 45 \mathrm{mg} \text {, followed by a dose of } 45 \mathrm{mg} \text { after } 4 \text { weeks and, } \\
\text { subsequently, every I } 2 \text { weeks }\end{array}$ & 5 & $€ 12,509$ \\
\hline
\end{tabular}

period) and the second (or subsequent) year of treatment (maintenance period only). Therefore, to capture the most significant differences among the biologic drugs considered in terms of both efficacy (NNT) and treatment costs, we calculated the mean cost treatment referred (1) to the first year considering the induction and the maintenance dosing scheme (Table 1) and (2) to the second (or subsequent) year considering only the maintenance dosing scheme (Table 2).

\section{Network meta-analysis}

This economic evaluation was based on the results of a recent cost analysis published in the United States, which evaluated the NNT versus placebo of adalimumab, etanercept, ixekizumab, secukinumab, and ustekinumab in the treatment of moderate-to-severe $\mathrm{PsO}$, respectively. ${ }^{23}$ Table 3 shows the NNT values considered. The NNT values, evaluated in the US cost analysis, ${ }^{23}$ were obtained from a previous network meta-analysis (NMA) of PASI75, PASI90, and PASI100 data of published randomized clinical trials, ${ }^{24}$ the results of which are presented in Table 4. The NMA was based on a systematic literature review (SLR) of published and gray literature, following guidelines from the Cochrane Handbook of Systematic Reviews and Interventions. ${ }^{25}$ The SLR covered the period from January 1990 to November 2015 and included phase II, III, and IV randomized controlled trials (RCTs) of relevant conventional systemic and biologic therapies in moderate-to-severe PsO. The NMA was presented as a poster at the ISPOR 2016 (International Society for Pharmacoeconomics and Outcomes Research).

We considered a longer time frame compared to the one reported in the NMA, which only looked at the first 1216 weeks of therapy (induction period) of randomized clinical trials. ${ }^{24}$ We hypothesized that response rates ${ }^{24}$ and
NNT values ${ }^{23}$ will remain constant over the first and the second (or subsequent) year of treatment.

\section{Treatments and costs}

Of the biologic drugs currently available in Italy for the treatment of moderate-to-severe $\mathrm{PsO}$, subcutaneous adalimumab, etanercept, ustekinumab, secukinumab, and ixekizumab were included in the analysis. Infliximab was not considered due to its different administration route (infusion). Biologics treatment costs were calculated for the total number of doses administered during the first (induction plus maintenance period) and the second years (maintenance period only) of treatment.

Calculation of costs of biologic therapies was based on the following assumptions: complete adherence to the indicated doses during the evaluated period, an ex-factory price per pack net of temporary discounts by law (AIFA Resolution of 3 July 2006, Official Gazette $n^{\circ} 156$ of 7 July 2006, and subsequent AIFA Resolution of 9 February 2007, Official Gazette $n^{\circ} 57$ of 9 March 2007 and extensions thereof), and any other discounts agreed with Italian NHS facilities. ${ }^{26,27}$

Administration and monitoring costs were not included in the analysis because, using the same route of administration (subcutaneous) for all biologic drugs, no difference in the consumption of resources was assumed.

\section{Sensitivity analysis}

A sensitivity analysis was conducted in order to evaluate the validity of the base case results ${ }^{28}$ and was focused on the NNT values estimated by the US study. ${ }^{23}$ All the NNT values were varied simultaneously to assess the impact of such changes on the mean cost per NNT. To this purpose, parameters were given the lower value of the respective $95 \%$ 
Table 2. Dosing scheme, number of administrations, and annual mean cost per patient in the second (and subsequent) year of treatment.

\begin{tabular}{|c|c|c|c|}
\hline Biologics & Dosage & $\begin{array}{l}\text { Number of } \\
\text { administrations } \\
\text { per year }\end{array}$ & $\begin{array}{l}\text { Annual mean } \\
\text { cost per patient }\end{array}$ \\
\hline Adalimumab & Dose of $40 \mathrm{mg}$ administered every other week & 26 & $€ I I, 032$ \\
\hline Etanercept branded & Dose of $50 \mathrm{mg}$ once a week & 52 & $€ I I, 973$ \\
\hline Etanercept biosimilar & Dose of $50 \mathrm{mg}$ once a week & 52 & $€ 7915$ \\
\hline Ixekizumab & Dose of $80 \mathrm{mg}$ every 4 weeks & 13 & $€ 10,443$ \\
\hline Secukinumab & $\begin{array}{l}\text { Monthly dose of } 300 \mathrm{mg} \text {. Each dose is administered } \\
\text { with two subcutaneous injections of } 150 \mathrm{mg}\end{array}$ & 12 & $€ 10,348$ \\
\hline Ustekinumab & Dose of $45 \mathrm{mg}$ every 12 weeks & 4,33 & $€ 10,832$ \\
\hline
\end{tabular}

Table 3. Number needed to treat per additional PASI75, PASI90, or PASII 00 responder versus placebo for each of the evaluated biologics. ${ }^{23}$

\begin{tabular}{|c|c|c|c|}
\hline \multirow[t]{2}{*}{ Treatment } & PASI75 & PASI90 & PASIIO0 \\
\hline & NNT (Cr.I.) & NNT (Cr.I.) & NNT (Cr.I.) \\
\hline Adalimumab (80 mg/40 mg EOW) & $1.9(1.6-2.4)$ & $3.5(2.5-4.9)$ & I I.8 (6.8-20.3) \\
\hline Etanercept (50 mg BIW) & $2.2(1.9-2.6)$ & $4.2(3.2-5.6)$ & I $5.9(\mid 0.2-24.1)$ \\
\hline Ixekizumab (80 mg Q2W) & $1.2(1.1-1.2)$ & $1.4(1.3-1.6)$ & $2.5(2.0-3.3)$ \\
\hline Secukinumab (300 mg) & $1.3(1.2-1.4)$ & I.7 (I.4-2.0) & $3.6(2.6-4.9)$ \\
\hline Ustekinumab (45 mg) & $1.6(1.4-1.8)$ & $2.4(2.0-3.1)$ & $6.7(4.6-10.0)$ \\
\hline
\end{tabular}

PASI: Psoriasis Area and Severity Index; NNT: number needed to treat; Cr.l.: credible interval; EOW: every other week; BIW: twice weekly; Q2W: every 2 weeks.

NNTs for adalimumab, etanercept, ixekizumab, secukinumab, and ustekinumab were calculated versus placebo, respectively.

Table 4. Conditional probabilities of achieving PASI75, PASI90, or PASII00 response versus placebo for the evaluated biologics. ${ }^{23}$

\begin{tabular}{|c|c|c|c|c|c|c|}
\hline \multirow[t]{2}{*}{ Treatment } & \multicolumn{2}{|l|}{ PASI75 } & \multicolumn{2}{|l|}{ PASI90 } & \multicolumn{2}{|l|}{ PASIIO0 } \\
\hline & Treatment & Placebo & Treatment & Placebo & Treatment & Placebo \\
\hline Adalimumab ( $80 \mathrm{mg} / 40 \mathrm{mg}$ EOW) & $57.0 \%$ & $4.4 \%$ & $30.7 \%$ & $0.8 \%$ & $9.2 \%$ & $0.1 \%$ \\
\hline Etanercept $(50 \mathrm{mg}$ BIW) & $50.4 \%$ & $4.4 \%$ & $25.0 \%$ & $0.8 \%$ & $6.7 \%$ & $0.1 \%$ \\
\hline Ixekizumab (80 mg Q2W) & $89.7 \%$ & $4.4 \%$ & $72.0 \%$ & $0.8 \%$ & $40.5 \%$ & $0.1 \%$ \\
\hline Secukinumab (300 mg) & $82.8 \%$ & $4.4 \%$ & $60.3 \%$ & $0.8 \%$ & $28.7 \%$ & $0.1 \%$ \\
\hline Ustekinumab (45 mg) ${ }^{\mathrm{a}}$ & $69.0 \%$ & $4.4 \%$ & $42.6 \%$ & $0.8 \%$ & $15.6 \%$ & $0.1 \%$ \\
\hline
\end{tabular}

PASI: Psoriasis Area and Severity Index; BIW: twice weekly; EOW: every other week; Q2W: every 2 weeks. aWe have excluded ustekinumab $90 \mathrm{mg}$, because an average weight per patient $<100 \mathrm{~kg}$ was considered.

credible interval (Cr.I.) in a former round and the higher value in the latter $(95 \%$ Cr.I. values are reported in Table 3$)$.

\section{Results}

\section{Cost per responder in the first year of treatment}

Separately for each of the three PASI responses, Table 5 shows the mean cost per responder in the first year of treatment for each of the five biologics considered. In this analysis ixekizumab appears to be associated with the least mean cost per responder among all comparators.
Overall, the differences in the mean cost per responder between ixekizumab and the other biologic therapies increase with higher PASI thresholds. The observed differences between ixekizumab and the other biologic therapies were smallest compared to secukinumab and highest with etanercept. For PASI75, the difference in the mean cost per responder between ixekizumab and the other biologics ranges from $€ 1549$ (vs secukinumab) to $€ 16,032$ (vs branded etanercept) (Figure 1); for PASI90, differences range from $€ 4336$ (vs secukinumab) to $€ 42,773$ (vs branded etanercept) (Figure 2). Considering PASI100, cost differences range from $€ 15,529$ (vs secukinumab) to $€ 200,166$ (vs branded etanercept) (Figure 3). 
Table 5. Cost per responder in the first year of treatment.

\begin{tabular}{|c|c|c|c|c|c|c|}
\hline Treatment & $\begin{array}{l}\text { NNT } \\
\text { PASI } \geqslant 75\end{array}$ & $\begin{array}{l}\text { Cost per } \\
\text { responder }\end{array}$ & $\begin{array}{l}\text { NNT } \\
\text { PASI } \geqslant 90\end{array}$ & $\begin{array}{l}\text { Cost per } \\
\text { responder }\end{array}$ & $\begin{array}{l}\text { NNT } \\
\text { PASI } \geqslant 100\end{array}$ & $\begin{array}{l}\text { Cost per } \\
\text { responder }\end{array}$ \\
\hline Adalimumab & 1.9 & $€ 22,574$ & 3.5 & $€ 4 I, 583$ & 11.8 & $€ \mid 40,196$ \\
\hline Etanercept branded & 2.2 & $€ 32,420$ & 4.2 & $€ 61,892$ & 15.9 & $€ 234,307$ \\
\hline Etanercept biosimilar & 2.2 & $€ 21,432$ & 4.2 & $€ 40,916$ & 15.9 & $€ 154,896$ \\
\hline Ixekizumab & 1.2 & $€ 16,388$ & 1.4 & $€ 19,119$ & 2.5 & $€ 34,|4|$ \\
\hline Secukinumab & 1.3 & $€ 17,937$ & 1.7 & $€ 23,456$ & 3.6 & $€ 49,671$ \\
\hline Ustekinumab & 1.6 & $€ 20,014$ & 2.4 & $€ 30,021$ & 6.7 & $€ 83,808$ \\
\hline
\end{tabular}

NNT: number needed to treat; PASI: Psoriasis Area and Severity Index.

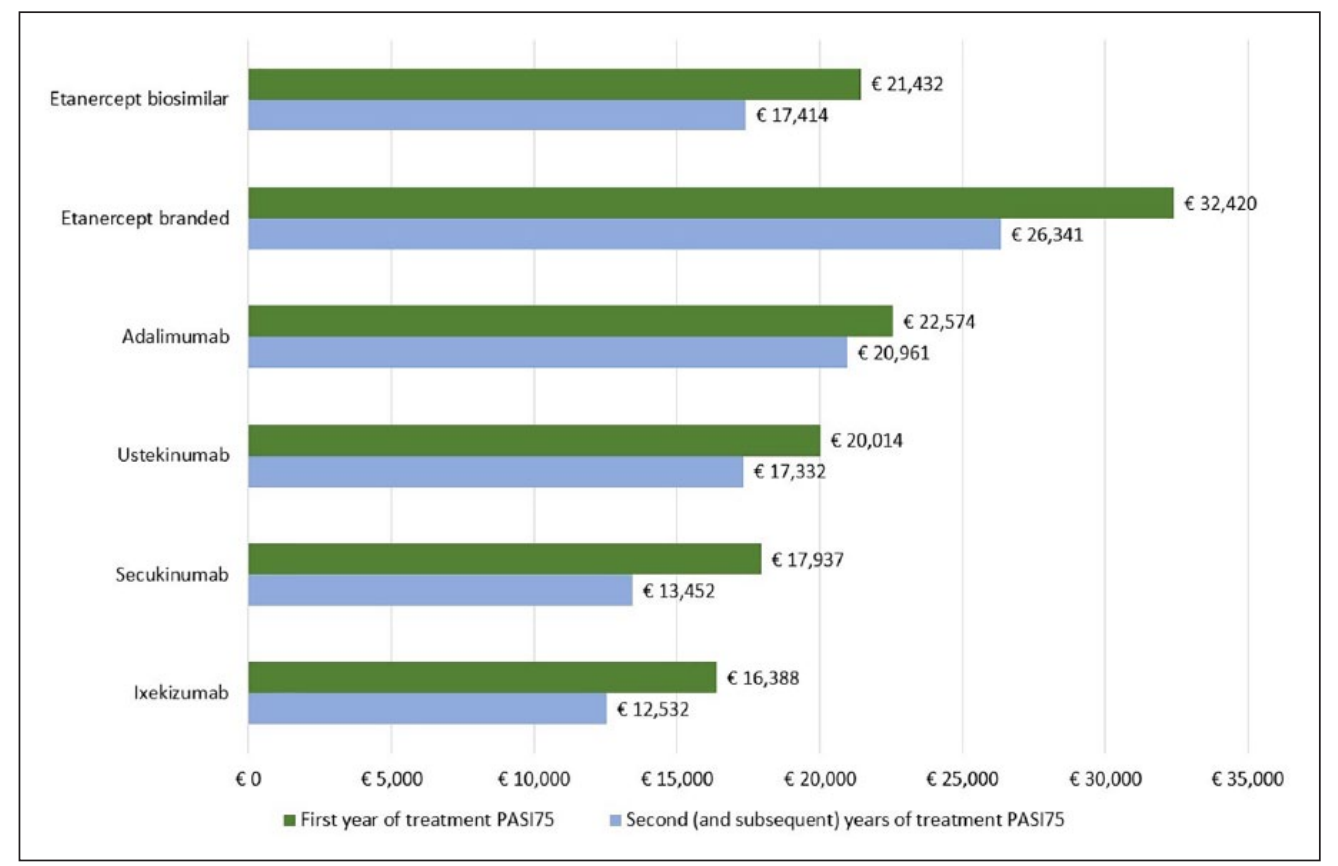

Figure I. Cost per responder PASI75 in the first year of treatment (induction plus maintenance period) and in the second (and subsequent) year of treatment (maintenance period only) for each of the evaluated biologics.

\section{Cost per responder in the second (and subsequent) year of treatment}

Table 6 reports the mean cost per responder for each of the five biologics in the second (or subsequent) year of treatment across all PASI responses. In line with the results for first-year cost per responder, ixekizumab shows the lowest mean cost per responder. In line with the outcomes in the first year of treatment, cost differences in favor of ixekizumab versus its competitors increase with increase in the PASI response. Again, the smallest differences appear in comparison with secukinumab.

Based on PASI75, the difference in the mean cost per responder in favor of ixekizumab ranges from $€ 921$ (vs secukinumab) to $€ 13,809$ (vs branded etanercept) (Figure 1). With PASI90, cost differences vary from $€ 2791$ (vs secukinumab) to $€ 35,667$ (vs branded etanercept) (Figure 2). For PASI100, the respective values range between
$€ 11,145$ (vs secukinumab) and $€ 164,267$ (vs branded etanercept) (Figure 3).

\section{Sensitivity analysis}

Table 7 shows the results of the sensitivity analysis where, for re-evaluating the NNT values, the lower and upper limits of the respective $95 \%$ Cr.I. values were adopted. In all comparisons, ixekizumab remains the therapy with the least mean cost per responder.

\section{Discussion}

As new biologics are being approved, adding to the number of treatment options for the management of $\mathrm{PsO}$, information on comparative treatment costs is increasingly important for decision-makers. NMA is a statistical approach to generate comparative efficacy data when 


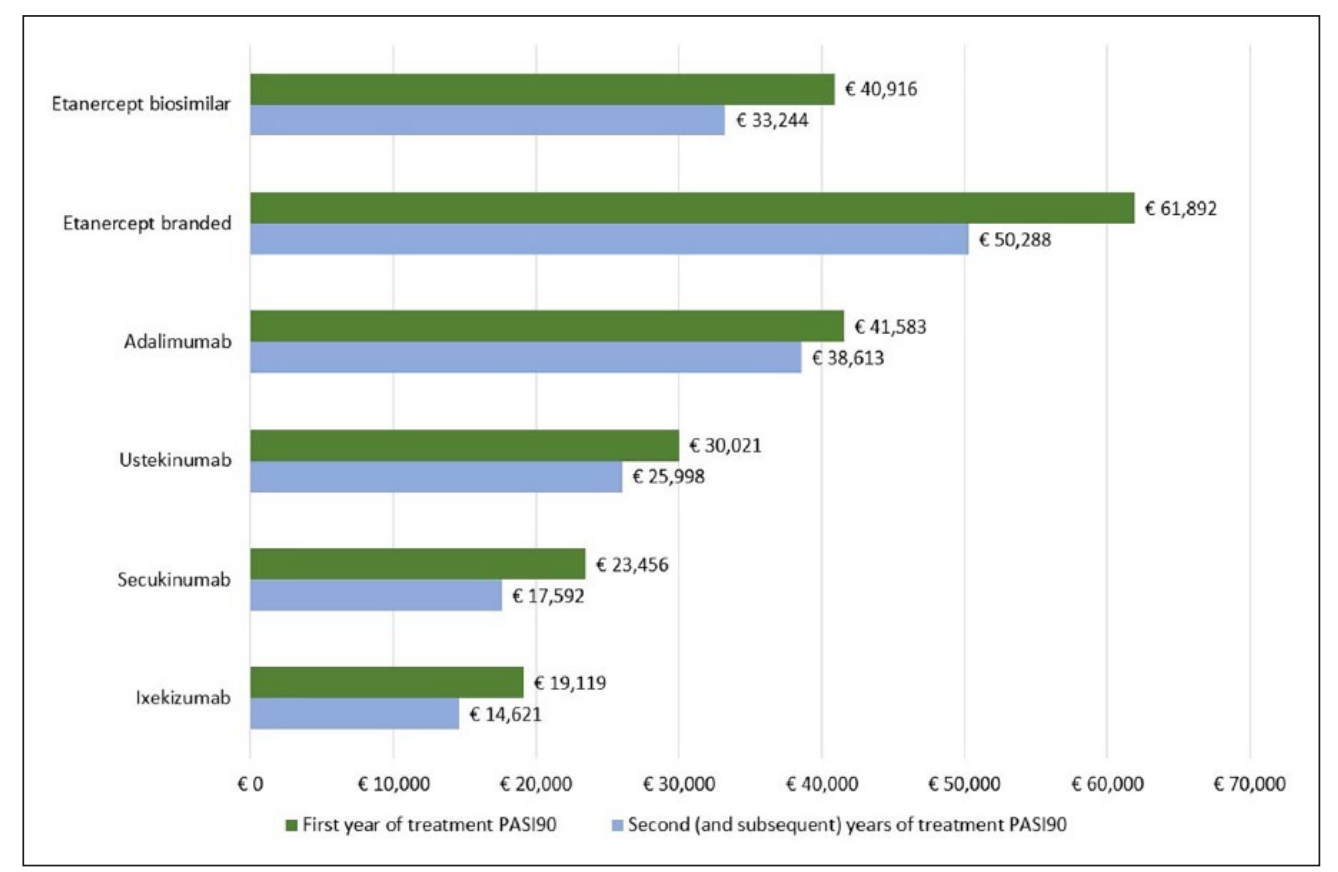

Figure 2. Cost per responder PASI90 in the first year of treatment (induction plus maintenance period) and in the second (and subsequent) year of treatment (maintenance period only) for each of the evaluated biologics.

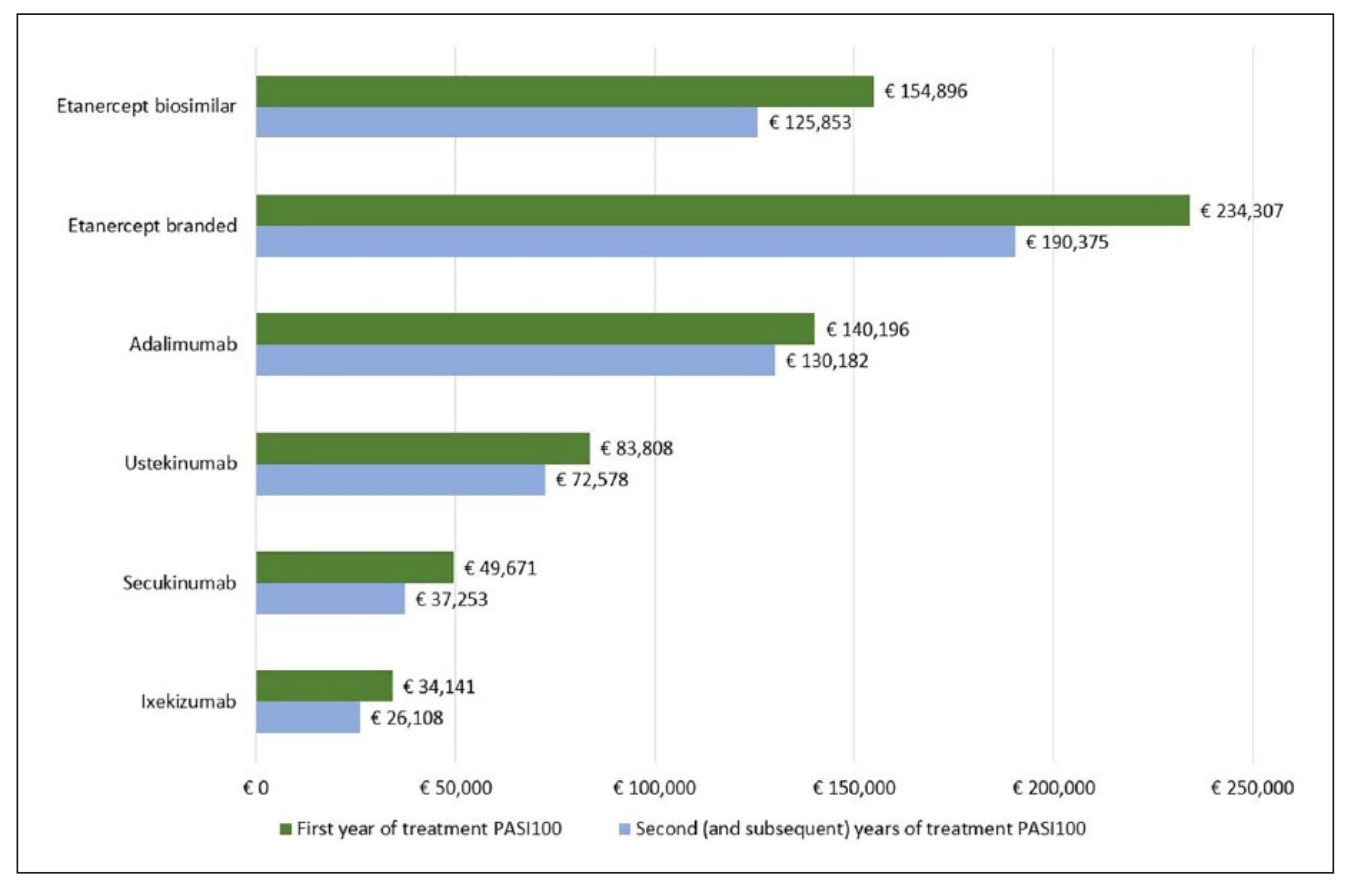

Figure 3. Cost per responder PASII 00 in the first year of treatment (induction plus maintenance period) and in the second (and subsequent) year of treatment (maintenance period only) for each of the evaluated biologics.

head-to-head trials are not available for all the treatments considered. ${ }^{29,30}$ Using this method, Hartz et al. ${ }^{24}$ recently highlighted the superiority of ixekizumab across all PASI response criteria (PASI75, PASI90, and PASI100) compared to placebo, secukinumab, ustekinumab, adalimumab, and etanercept. Based on the NNT values quantified in the US cost analysis, ${ }^{23}$ the cost per responder (as compared to placebo) was calculated, as a combined indicator of both the clinical benefit and the treatment cost associated with each of the five biologic subcutaneous drugs approved for the treatment of moderate-to-severe $\mathrm{PsO}$ in Italy. 
Table 6. Cost per responder in the second (and subsequent) year of treatment.

\begin{tabular}{|c|c|c|c|c|c|c|}
\hline Biologics & $\begin{array}{l}\text { NNT } \\
\mathrm{PASI} \geqslant 75\end{array}$ & $\begin{array}{l}\text { Cost per } \\
\text { responder }\end{array}$ & $\begin{array}{l}\text { NNT } \\
\text { PASI } \geqslant 90\end{array}$ & $\begin{array}{l}\text { Cost per } \\
\text { responder }\end{array}$ & $\begin{array}{l}\text { NNT } \\
P A S I \geqslant 100\end{array}$ & $\begin{array}{l}\text { Cost per } \\
\text { responder }\end{array}$ \\
\hline Adalimumab & 1.9 & $€ 20,96 I$ & 3.5 & $€ 38,613$ & 11.8 & $€ 130,182$ \\
\hline Etanercept branded & 2.2 & $€ 26,341$ & 4.2 & $€ 50,288$ & 15.9 & $€ 190,375$ \\
\hline Etanercept biosimilar & 2.2 & $€|7,4| 4$ & 4.2 & $€ 33,244$ & 15.9 & $€ 125,853$ \\
\hline Ixekizumab & 1.2 & $€ 12,532$ & $\mathrm{I} .4$ & $€|4,62|$ & 2.5 & $€ 26,108$ \\
\hline Secukinumab & 1.3 & $€ 13,452$ & 1.7 & $€ 17,592$ & 3.6 & $€ 37,253$ \\
\hline Ustekinumab & 1.6 & $€ 17,332$ & 2.4 & $€ 25,998$ & 6.7 & $€ 72,578$ \\
\hline
\end{tabular}

NNT: number needed to treat; PASI: Psoriasis Area and Severity Index.

Table 7. Sensitivity analysis (95\% credible intervals).

\begin{tabular}{|c|c|c|c|c|c|c|}
\hline \multirow[t]{2}{*}{ Biologics } & \multicolumn{2}{|c|}{ Cost per NNT PASI75 } & \multicolumn{2}{|c|}{ Cost per NNT PASI90 } & \multicolumn{2}{|c|}{ Cost per NNT PASII 00} \\
\hline & $\begin{array}{l}\text { Lower } \\
\text { 95\% Cr.l. }\end{array}$ & $\begin{array}{l}\text { Upper } \\
\text { 95\% Cr.I. }\end{array}$ & $\begin{array}{l}\text { Lower } \\
\text { 95\% Cr.I. }\end{array}$ & $\begin{array}{l}\text { Upper } \\
95 \% \text { Cr.I. }\end{array}$ & $\begin{array}{l}\text { Lower } \\
\text { 95\% Cr.I. }\end{array}$ & $\begin{array}{l}\text { Upper } \\
95 \% \text { Cr.I. }\end{array}$ \\
\hline \multicolumn{7}{|l|}{ Induction and maintenance } \\
\hline Adalimumab & $€ 19,010$ & $€ 28,5 \mid 4$ & $€ 29,702$ & $€ 58,2 \mid 7$ & $€ 80,791$ & $€ 24 I, \mid 84$ \\
\hline Etanercept originator & $€ 27,999$ & $€ 38,3 \mid 4$ & $€ 47,156$ & $€ 82,523$ & $€|50,3| 0$ & $€ 355,145$ \\
\hline Etanercept biosimilar & $€ 18,510$ & $€ 25,329$ & $€ 31,174$ & $€ 54,555$ & $€ 99,367$ & $€ 234,780$ \\
\hline Ixekizumab & $€ 15,022$ & $€ 16,388$ & $€ 17,753$ & $€ 21,850$ & $€ 27,313$ & $€ 45,066$ \\
\hline Secukinumab & $€ 16,557$ & $€ 19,3 \mid 6$ & $€ 19,3 \mid 6$ & $€ 27,595$ & $€ 35,873$ & $€ 67,607$ \\
\hline Ustekinumab & $€|7,5| 2$ & $€ 22,516$ & $€ 25,017$ & $€ 38,777$ & $€ 57,540$ & $€ 125,087$ \\
\hline \multicolumn{7}{|l|}{ Maintenance } \\
\hline Adalimumab & $€ 17,652$ & $€ 26,478$ & $€ 27,58 \mathrm{I}$ & $€ 54,059$ & $€ 75,020$ & $€ 223,957$ \\
\hline Etanercept originator & $€ 22,749$ & $€ 31,130$ & $€ 38,3 \mid 4$ & $€ 67,050$ & $€ \mid 22,127$ & $€ 288,555$ \\
\hline Etanercept biosimilar & $€ 15,039$ & $€ 20,580$ & $€ 25,329$ & $€ 44,326$ & $€ 80,736$ & $€ 190,759$ \\
\hline Ixekizumab & $€ \mid I, 488$ & $€ 12,532$ & $€ \mid 3,576$ & $€ 16,709$ & $€ 20,886$ & $€ 34,463$ \\
\hline Secukinumab & $€|2,4| 8$ & $€ \mid 4,487$ & $€ \mid 4,487$ & $€ 20,696$ & $€ 26,905$ & $€ 50,706$ \\
\hline Ustekinumab & $€ 15,165$ & $€ 19,498$ & $€ 21,665$ & $€ 33,581$ & $€ 49,829$ & $€ 108,325$ \\
\hline
\end{tabular}

NNT: number needed to treat; PASI: Psoriasis Area and Severity Index; Cr.l.: credible interval.

Independent of the PASI response criteria used to calculate the NNT, ixekizumab yielded the numerically lowest mean cost per responder, in both the first (induction plus maintenance period) and the second (maintenance period only) years of treatment. The results from this analysis show a more favorable difference between the mean cost per responder of ixekizumab and the mean cost per responder of the other biologic drugs evaluated, which increase with using more stringent PASI response criteria (PASI90 and PASI100). According to the European S3-Guidelines, reaching a PASI75 response has been accepted as the minimum clinically significant improvement. 13,31,32 Important in this context is the impact of skin improvement on the patients' health-related quality of life (HRQoL). In fact, achieving clear or almost clear skin (PASI90 and PASI100) has been shown to better correlate with HRQoL improvement and therefore should become the new standard therapeutic target. ${ }^{33,34}$

Our results are in line with a recent Spanish analysis where, based on the same methods, the highest costeffectiveness (mean cost per responder) was found for ixekizumab versus adalimumab, etanercept, secukinumab, and ustekinumab in the treatment of moderate-to-severe $\mathrm{PsO}$ in both the first (induction plus maintenance period) and the following (maintenance period only) treatment years. ${ }^{35}$

A limitation of this analysis is owed to the fact that efficacy results from a NMA and not from all head-to-head comparisons were used. However, a wide range of sensitivity analysis has confirmed NMA reliable to achieve solid results. ${ }^{24}$

A second limitation refers to the long-term extrapolation of NMA's short-term clinical outcomes. While for the NMA only the induction period (12-16weeks) was considered, which prevented the assessment of the relative efficacy of ixekizumab (and other biologic drugs) over longer time periods, we assumed that response rates ${ }^{24}$ and related NNT values ${ }^{23}$ remain constant over the first and the second (or subsequent) years of treatment. Such assumption was made with the purpose of providing decision-makers with data for a comparison not limited to the induction period, but extended to a longer time horizon (at least 
12-24 months) so that it can serve for drawing up spending budgets. Unfortunately, there are no published studies that could confirm 12- and 24-month effectiveness.

Although biologic drugs are associated with significant improvements in QoL for patients with PsO, ${ }^{15}$ the current analysis did not take into account any measurement of HRQoL. Due to the same route of administration for all biologic drugs considered in this analysis, costs associated with administration and monitoring were excluded.

\section{Conclusion}

In this analysis, ixekizumab consistently emerged as the best treatment for moderate-to-severe $\mathrm{PsO}$ when compared to adalimumab, etanercept, secukinumab, and ustekinumab. This cost-per-responder assessment indicates ixekizumab as the most cost-effective treatment option from the perspective of the Italian NHS.

\section{Declaration of conflicting interests}

R.R. and A.C. declare no conflict of interest. S.A., A.M. and S.L. are full-time employees of Eli Lilly Italia SpA.

\section{Funding}

This research was made possible by an educational grant from Eli Lilly Italia SpA.

\section{ORCID iD}

Roberto Ravasio (iD https://orcid.org/0000-0002-5477-1957

\section{References}

1. Di Meglio P, Villanova F and Nestle FO. Psoriasis. Cold Spring Harb Perspect Med 2014; 4(8): a015354.

2. Boehncke WH and Schön MP. Psoriasis. Lancet 2015; 386(9997): 983-994.

3. Menter A, Gottlieb A, Feldman SR, et al. Guidelines of care for the management of psoriasis and psoriatic arthritis: section 1. J Am Acad Dermatol 2008; 58(5): 826-850.

4. Parisi R, Symmons DP, Griffiths CE, et al. Global epidemiology of psoriasis: a systematic review of incidence and prevalence. $J$ Invest Dermatol 2013; 133(2): 377-385.

5. Kurd SK, Troxel AB, Crits-Christoph P, et al. The risk of depression, anxiety, and suicidality in patients with psoriasis: a population-based cohort study. Arch Dermatol 2010; 146(8): 891-895.

6. Gelfand JM, Troxel AB, Lewis JD, et al. The risk of mortality in patients with psoriasis: results from a population-based study. Arch Dermatol 2007; 143(12): 1493-1499.

7. World Health Organization. Global report on psoriasis, http ://apps.who.int/iris/bitstream/handle/10665/204417 /9789241565189_eng.pdf;jsessionid=8CD825833000E4EC5 F1AA0223101E7AE?sequence=1 (accessed May 2018).

8. Chandran V and Raychaudhuri SP. Geoepidemiology and environmental factors of psoriasis and psoriatic arthritis. $J$ Autoimmun 2010; 34(3): J314-J321.

9. Naldi L, Colombo P, Placchesi EB, et al. Study design and preliminary results from the pilot phase of the PraKtis study: self-reported diagnoses of selected skin diseases in a representative sample of the Italian population. Dermatology 2004; 208(1): 38-42.

10. Saraceno R, Mannheimer R and Chimenti S. Regional distribution of psoriasis in Italy. $J$ Eur Acad Dermatol Venereol 2008; 22(3): 324-329.

11. Vena GA, Altomare G, Ayala F, et al. Incidence of psoriasis and association with comorbidities in Italy: a 5-year observational study from a national primary care database. Eur J Dermatol 2010; 20(5): 593-598.

12. Icen M, Crowson CS, McEvoy MT, et al. Trends in incidence of adult-onset psoriasis over three decades: a populationbased study. J Am Acad Dermatol 2009; 60(3): 394-401.

13. Pathirana D, Ormerod AD, Saiag $\mathrm{P}$, et al. European $\mathrm{S} 3$-guidelines on the systemic treatment of psoriasis vulgaris. J Eur Acad Dermatol Venereol. 2009; 23(Suppl. 2): 1-70.

14. Gisondi $\mathrm{P}$, Altomare $\mathrm{G}$, Ayala F, et al. Italian guidelines on the systemic treatments of moderate-to-severe plaque psoriasis. $J$ Eur Acad Dermatol Venereol 2017; 31(5): 774-790.

15. Blauvelt A, Griffiths CE, Lebwohl M, et al. Reaching complete or near-complete resolution of psoriasis: benefit and risk considerations. Br J Dermatol 2017; 177(2): 587-590.

16. Farahnik B, Beroukhim K, Zhu TH, et al. Ixekizumab for the treatment of psoriasis: a review of phase III trials. Dermatol Ther 2016; 6(1): 25-37.

17. Thaci D, Blauvelt A, Reich K, et al. Secukinumab is superior to ustekinumab in clearing skin of subjects with moderate to severe plaque psoriasis: CLEAR, a randomized controlled trial. J Am Acad Dermatol 2015; 73(3): 400-409.

18. Griffiths CEM, Reich K, Lebwohl M, et al. Comparison of ixekizumab with etanercept or placebo in moderate-to-severe psoriasis (UNCOVER-2 and UNCOVER-3): results from two phase 3 randomised trials. Lancet 2015; 386(9993): 541-551.

19. Egeberg A. Phase 3 trials of ixekizumab in moderate-to-severe plaque psoriasis. N Engl J Med 2016; 375(21): 2101-2102.

20. Reich K, Pinter A, Lacour JP, et al. Comparison of ixekizumab with ustekinumab in moderate-to-severe psoriasis: 24-week results from IXORA-S, a phase III study. Br J Dermatol 2017; 177(4): 1014-1023.

21. Kristensen LE, Christensen R, Bliddal H, et al. The number needed to treat for adalimumab, etanercept, and infliximab based on ACR50 response in three randomized controlled trials on established rheumatoid arthritis: a systematic literature review. Scand J Rheumatol 2007; 36(6): 411-417.

22. Barra L, Pope JE and Payne M. Real-world anti-tumor necrosis factor treatment in rheumatoid arthritis, psoriatic arthritis, and ankylosing spondylitis: cost-effectiveness based on number needed to treat to improve health assessment questionnaire. J Rheumatol 2009; 36(7): 1421-1428.

23. Al Sawah S, Foster SA, Burge R, et al. Cost per additional responder for ixekizumab and other FDA-approved biologics in moderate-to-severe plaque psoriasis. $J$ Med Econ 2017; 20: 1224-1230.

24. Hartz S, Dutronc Y, Kiri SH, et al. Network meta-analysis to evaluate the efficacy of ixekizumab in the treatment of moderate-to-severe psoriasis. In: International Society for Pharmacoeconomics and Outcomes Research's 19th annual European congress, Vienna, 29 October-2 November 2016.

25. JPT Higgins and S Green (eds). Cochrane handbook for systematic reviews of interventions (Version 5.1.0). London: The Cochrane Collaboration, 2011. 
26. Regione del Veneto Coordinamento Regionale Unico sul Farmaco-CRUF. Allegato A al Decreto n. 92 del 25 luglio, 2017. Available at: https://bur.regione.veneto.it/BurvServices /pubblica/Download.aspx?name=92_Allegato_350429. pdf\&type $=7 \&$ storico $=$ False (accessed February 2018).

27. SocietàdiCommittenzaRegionePiemonteS.p.A.NEW Allegato 1-Tabella farmaci aggiudicati con prezzi-primo, secondo, terzo, quarto, quinto confronto (aggiornamento al 12 February 2018) (Aggiornati i lotti 251, 252, 253, 674, 1862, 2229, 2350), http://www.scr.piemonte.it/cms/acquisti-forniture-e-servizi /convenzioni/convenzioni-attive/1847-fornitura-di-farmaci -ospedalieri-e-farmaci-necessari-alla-distribuzione-diretta -con-il-metodo-in-nome-e-per-conto-gara-66-2015 -aggiornamento-al-quinto-confronto-concorrenziale.html (accessed February 2018).

28. Associazione Italiana di Economia Sanitaria (AIES). Proposte di linee guida per la valutazione economica degli interventi sanitari. Pharmacoeconom Ital Res 2009; 11(2): 89-93.

29. Greco T, Biondi-Zoccai G, Saleh O, et al. The attractiveness of network meta-analysis: a comprehensive systematic and narrative review. Heart Lung Vessel 2015; 7(2): 133-142.
30. Greco T, Landoni G, Biondi-Zoccai G, et al. A Bayesian network meta-analysis for binary outcome: how to do it. Stat Methods Med Res 2016; 25(5): 1757-1773.

31. Nast A, Gisondi P, Ormerod AD, et al. European S3-guidelines on the systemic treatment of psoriasis vulgaris - update 2015-short version-EDF in cooperation with EADV and IPC. J Eur Acad Dermatol Venereol 2015; 29(12): 2277-2294.

32. Mrowietz U, Kragballe K, Reich K, et al. Definition of treatment goals for moderate to severe psoriasis: a European consensus. Arch Dermatol Res 2011; 303(1): 1-10.

33. Puig L. PASI90 response: the new standard in therapeutic efficacy for psoriasis. J Eur Acad Dermatol Venereol 2015; 29(4): 645-648.

34. Strober B, Papp KA, Lebwohl M, et al. Clinical meaningfulness of complete skin clearance in psoriasis. $J \mathrm{Am}$ Acad Dermatol 2016; 75(1): 77-82.e7.

35. Huete T, Núñez M, Sacristán JA, et al. Evaluation of the efficiency of the biologic therapies in the treatment of moderateto-severe plaque of psoriasis in Spain: analysis of cost per NNT. In: 45th Spanish national congress of dermatology and venereology (AEDV), Madrid, 10-13 May 2017. 